\title{
O valor enorme das palavras
}

\author{
Wander Melo Miranda \\ Universidade Federal de Minas Gerais
}

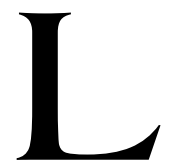

iteratura e experiência confundem-se na obra de Graciliano Ramos como se fossem a urdidura de uma trama comum. Romances, memórias, contos e textos circunstanciais parecem repetir a afirmação do escritor - "Nunca pude sair de mim mesmo. Só posso escrever o que sou" -, chamando a atenção para o espaço autobiográfico em que sua obra se insere. À primeira vista parecerá ao leitor uma perspectiva redutora, encerrada nos limites de uma subjetividade que reduz o mundo a dimensão muito particular ou a visão demasiadamente referencial. Mas à medida que se avança na leitura de livros como Angústia (1936) ou Infância (1945), nos quais traços da personalidade do autor e episódios de sua vida pessoal aparecem fortemente marcados - pela via da ficção ou da autobiografia -, a expectativa do leitor se transforma.

A aderência textual à vida concreta é acompanhada da superação de seus limites autobiográficos ou referenciais, compondo o paradoxo da misteriosa química da obra de Graciliano Ramos. Visto de hoje, seu compromisso político-partidário é um complicador a mais. Legítimo em suas aspirações e coerente do ponto de vista ideológico - Graciliano pertenceu aos quadros do Partido Comunista Brasileiro de 1945 até a morte -, seu engajamento retrata um período crucial da história brasileira, que culmina com o Estado Novo getulista. Indiscutivelmente articulado com a prática literária que constitui, em nenhum momento faz essa prática resvalar para as facilidades do panfleto ou ceder à sedução das relações imediatas. Ao contrário, em razão do conflito que apresentam entre texto e história, sujeito e discurso, memória e imaginação, seus livros se abrem a uma série de indagações experimentais que, desde o romance de estréia, Caetés (1933), desautorizam toda sorte de respostas excludentes e definitivas, para espanto do leitor e dos próprios narradores colocados em cena pelo autor, sejam eles autobiográficos ou não.

${ }^{1}$ SENNA, 1957, p. 238. A entrevista foi publicada pela primeira vez em 1948. 
No território minado por onde transitam suas personagens, em busca de uma unidade de antemão impossível no decurso da experiência desdobrada no tempo, não há lugar para ilusões compensatórias ou processos conciliadores de integração social. Seres à margem, João Valério, Luís da Silva, os retirantes de Vidas secas, o menino de Infância, os presos de Memórias do cárcere, e mesmo Paulo Honório, trazem todos a marca da "desgraça irremediável que os açoita", ${ }^{2}$ para usar as palavras do escritor, que deles se aproxima solidário, com uma simpatia ora mais, ora menos distanciada, sempre comovente na cautela com que se expõe.

Mesmo o recurso à memória, de que o narrador na maioria das vezes se vale, não conduz ao abrigo das certezas apaziguadoras e da verdade incontestável, espaço que é da contradição e da recorrência desintegradoras. No ato de recompor a vida pela linguagem, de ser escrevendo, a idéia do conhecimento de si a que chegam os narradores de Graciliano resulta numa construção móvel e aleatória, fruto de um saber precário, provisório nas suas conclusões e céptico no tocante à validade de suas premissas. Talvez por isso, nada resista em pé diante do desejo de destruir, segundo Otto Maria Carpeaux, o "edifício da nossa civilização artificial - cultura e analfabetismo letrados, sociedade, cidade, Estado, todas as autoridades temporais e espirituais". ${ }^{3}$ Destruição para transformar, para reverter por "linhas tortas" as diretrizes e os valores que o incipiente processo de modernização brasileira começava a implantar no país nas primeiras décadas do século 20. Opacas da perspectiva hegemônica do saber racionalizante, regiões sombrias da ordem atingem então o primeiro plano do texto, onde avultam na sua concretude dolorosa de violência excludente, de alteridade em vias de revelação.

Nas brechas abertas numa modernidade assim desencantada, firme na sua disposição de ir contra a amnésia histórica e social, Graciliano torna efetiva, talvez como nenhum outro escritor entre nós, a possibilidade de uma prática política do texto artístico. Daí o papel fundamental desempenhado pela memória em seus livros. Operadora da diferença e trabalhando com pontos de esquecimento da história oficial, ela se formula como atividade produtiva, que tece com as idéias e imagens do presente a experiência do passado, sempre renovada, refeita, recriada - vida e morte, vida contra a morte.

\footnotetext{
${ }^{2}$ SCHMIDT et al., 1943, p. 29.

${ }^{3}$ CARPEAUX, 1943, p. 350.
} 
A possibilidade da reminiscência descortina-se justamente onde a história triunfante dos "homens gordos do primado espiritual" " procede ao cancelamento do que ficou para trás, ou seja, no detalhe, no pequeno, no insignificante, a partir deles e com eles, como revelam Infância (1945) e Memórias do cárcere (1953).

Escritos no decorrer de quase seis anos, os capítulos de Infâncialivro de memórias e romance de formação - aparecem esparsos em um periódico de Alagoas, antes de adquirir a forma de livro. A contrapelo da maioria de realizações similares, distancia-se do tom nostálgico ou condescendente no tocante à rememoração do passado, optando por uma visão irônica, muitas vezes sarcástica em relação às injustiças sofridas e impiedosa diante do absurdo das situações representadas. Como seria de se esperar de um escritor como Graciliano, sua primeira narrativa assumidamente autobiográfica é corajosa e original, uma obra-prima de alto nível ético e artístico, raras vezes atingido pela literatura brasileira.

Em virtude das peculiaridades de sua execução, as memórias são compostas por blocos narrativos aparentemente autônomos, em que "cada relato isolado por um título tem o corte conclusivo e, ao mesmo tempo, suspensivo dos folhetins distribuídos por entregas". ${ }^{5}$ Para tanto, o narrador vale-se do desdobramento do eu nas inúmeras figuras retratadas que intitulam os relatos - "Padre José Inácio", "O moleque José", "José da Luz", "D. Maria", "Chico Brabo", José Leonardo", entre muitos outros. Cada um deles, como imagem num espelho, reflete as várias etapas da socialização do menino, sua difícil aprendizagem da escrita e da leitura. O ato de refletir, em que a construção do eu se faz através do intercâmbio com a experiência do outro, reforça o aspecto coletivo da memória individual, distanciando o memorialista da perspectiva narcísica a que poderia ver-se levado.

$\mathrm{Na}$ elaboração do texto, a estrutura folhetinesca dos relatos orais ouvidos na infância, bem como a dos livros de capa-e-espada lidos com prazer à época, é assimilada em função de uma prática memorialística também "suspensiva", que se distingue pela natureza fragmentária, nebulosa e lacunar da reminiscência. Nos três primeiros capítulos - "Nuvens", "Manhã", "Verão" -, o adulto busca colocar-se no lugar da criança, operando um deslocamento que simula o momento inaugural da reminiscência, no qual o sujeito que lembra e o objeto da lembrança apresentam-se de forma indistinta.

\footnotetext{
${ }^{4}$ RAMOS, 1953, v. 1, p. 7.

${ }^{5}$ LEITÃO, 2003, p. 273.
} 
A primeira coisa que guardei na memória foi um vaso de louça vidrada, cheio de pitombas, escondido atrás de uma porta. Ignoro onde o vi, quando o vi, e se uma parte do caso remoto não desaguasse noutro posterior, julgá-lo-ia sonho. Talvez nem me recorde bem do vaso: é possível que a imagem, brilhante e esguia, permaneça por eu a ter comunicado a pessoas que a confirmaram. ${ }^{6}$

O trecho citado é rico em sugestões. Nele o narrador hesita, recorre à lembrança alheia para construir a sua, depara-se com um primeiro obstáculo, expresso pelo vaso escondido atrás de uma porta. Composto por fragmentos narrativos e estilhaços de imagens, o capítulo "Nuvens" é uma sorte de poética da memória, do modo como ela atua e dos interditos que lhe são inerentes: a reconstrução penosa da história do Papa-hóstia, no decorrer da escrita, exprime o modo como a lembrança se torna relato. Em "Manhã”, as recordações iniciais do adulto-menino vão aos poucos tomando corpo, sem conseguir reverter de todo suas lacunas: "Naquele tempo a escuridão se ia dissipando, vagarosa. Acordei, reuni pedaços de pessoas e de coisas, pedaços de mim mesmo que boiavam no passado confuso, articulei tudo, criei o meu pequeno mundo incongruente."7 Em "Verão", figuras e acontecimentos já se recortam mais nitidamente, embora a luminosidade que o título expressa não desfaça as incertezas ou lacunas do mundo enfim rememorado: "Desse antigo verão que me alterou a vida restam ligeiros traços apenas. E nem deles posso afirmar que efetivamente me recorde. O hábito me leva a criar um ambiente, imaginar fatos a que atribuo realidade." 8

Por associações e derivações, as memórias se escrevem como ficção, libertam-se da determinante documental e abrem espaço para a reinvenção do eu que escreve diante da imagem pouco a pouco descortinada de si e dos outros. Ressaltam, com insistência, as vicissitudes da criança, a dura aprendizagem da norma familiar e da lei social, incorporadas como instâncias privilegiadas da opressão - "Eu vivia numa grande cadeia. Não, vivia numa cadeia pequena, como papagaio amarrado na gaiola." 9

\footnotetext{
${ }^{6}$ RAMOS, 2003, p. 9.

${ }^{7}$ RAMOS, 2003, p. 21.

${ }^{8}$ RAMOS, 2003, p. 27.

${ }^{9}$ RAMOS, 2003, p. 220-221.
} 
Como é de se supor, a alfabetização iniciada em casa é difícil e penosa. As repreensões do pai, Sebastião Ramos, o custo para aprender as primeiras letras, a confusão que faz do $t \operatorname{com}$ o $d$, a palmatória, as lágrimas, tudo isso acaba por indispor o menino com a escola em Buíque, onde, no volume do Barão de Macaúbas, encontra de novo o incompreensível Terteão do provérbio com o qual já implicara em casa - "Fala pouco e bem, ter-te-ão por alguém." ${ }^{10}$

Apesar da construção empolada da frase, a lição será posteriormente seguida à risca, quando o futuro escritor fará da linguagem concisa e conforme as regras gramaticais as marcas predominantes de seu estilo inconfundível. A antipatia inicial em relação às letras e aos livros é pouco a pouco vencida; o menino toma gosto pela leitura - refúgio e consolo da rejeição que sofre. Primeiro, mediante os livros emprestados da biblioteca do tabelião Jerônimo Barreto: folhetins de capa-e-espada, Júlio Verne, Joaquim Manuel de Macedo, José de Alencar. Depois, pelas obras naturalistas que lhe indica o literato, professor e agente dos Correios, Mário Venâncio. É ele o grande incentivador para que Graciliano e o primo Cícero de Vasconcelos criem um jornal. O primeiro número de O Dilúculo (que significa alvorada) vem à luz em 24 de junho de 1904, trazendo o conto de estréia do jovem autor, intitulado "O pequeno pedinte" e emendado por Venâncio de tal maneira a tornar quase irreconhecível sua forma original.

O primeiro contato do menino com a leitura é impregnado de dogmatismo: leitura unívoca, presa ao pé da letra e a parâmetros coercitivos, agravados pelas violentas reprimendas paternas - marca de fogo que se inscreve para sempre no texto do filho. Mas a descoberta da possibilidade de "falar pelo avesso" ${ }^{11}$ e assim participar do jogo ambíguo de "malícia e bondade" ${ }^{12}$ que as palavras encerram, tem como resultado uma nova modalidade de leitura - irônica - dos livros e do mundo. O menino vai, então, além dos insossos compêndios escolares, esgota a biblioteca de Jerônimo Barreto em busca de "aventuras, justiça, amor, vinganças," ${ }^{13}$ aceita a orientação generosa de Mário Venâncio, que amplia seus horizontes como leitor.

\footnotetext{
${ }^{10}$ RAMOS, 2003, p. 114.

${ }^{11}$ RAMOS, 2003, p. 203.

${ }^{12}$ RAMOS, 2003, p. 204.

${ }^{13}$ RAMOS, 2003, p. 229.
} 
A univocidade que as palavras - "armas terríveis" 14 - faziam supor desfaz-se ante a mobilidade e a multiplicação do significante textual, como os livros posteriores do adulto-escritor irão demonstrar. A posse desse saber é dolorosa e se marca no corpo da criança durante as crises periódicas de oftalmia, que agravam sua solidão e seu desamparo. Mais uma vez, como nas primeiras reminiscências do menino, luz e escuridão sintetizam as reverberações de sentido que impregnam a experiência sofrida de vencer a dor - de não poder ver e não poder falar.

Como relatado em "Cegueira", o menino permanece afastado das pessoas por várias semanas, com o rosto envolto por um pano escuro, a esconder os olhos vermelhos e inflamados. Além da dor física, sofre a antipatia que a mãe lhe manifesta, apelidando-o de "bezerro encourado" e cabra-cega".

Bezerro-encourado é um intruso. Quando uma cria morre, tiram-lhe o couro, vestem com ele um órfão, que, neste disfarce, é amamentado. A vaca sente o cheiro do filho, engana-se e adota o animal. Devo o apodo ao meu desarranjo, à feiúra, ao desengonço (...) Essa injúria revelou muito cedo minha condição na família: comparado ao bicho infeliz, considerei-me um pupilo enfadonho, aceito a custo. ${ }^{15}$

A percepção aguçada pela dor reverte a cegueira e delineia um ponto de fuga à situação de intruso: "Na escuridão percebi o valor enorme das palavras." ${ }^{16}$ Sons e ruídos adquirem sentido, velhas histórias são recuperadas, o menino enfim encontra um lugar na família, à margem, por certo, como o do avô paterno, retratado no relato "Manhã". O narrador detém-se aí na solitária tarefa do avô de confeccionar urupemas (peneiras) e, identificandose com ele, revela que trançar urupemas e traçar letras no papel são atividades análogas. Em ambas prevalece o ato de fazer, a lida artesanal, paciente e obsessiva com as fibras vegetais ou com as palavras; são atividades "desinteressadas", alheias à função utilitária que porventura possam ter; não visam a reiteração de modelos anteriores, mas são o meio particular de expressão de uma necessidade imperiosa, que é principalmente necessidade de depuração dos recursos utilizados: "procurou os seus caminhos e

\footnotetext{
${ }^{14}$ RAMOS, 2003, p. 109.

${ }^{15}$ RAMOS, 2003, p. 144.

${ }^{16}$ RAMOS, 2003, p. 146.
} 
executou urupemas fortes, seguras. Provavelmente não gostavam delas: prefeririam vê-las tradicionais e corriqueiras, enfeitadas e frágeis." ${ }^{17}$

Com as fibras da região o avô faz suas urupemas; com a fala regional o neto-escritor irá construir sua linguagem. Não se trata de transcrição lingüística, mas de transcriação. O uso de um mínimo de recursos para alcançar uma máxima expressividade parte da reelaboração do coloquial sertanejo, que conserva expressões portuguesas do século XVI, arcaizadas em Portugal, mas de uso comum no sertão nordestino. ${ }^{18}$ A oposição à grandiloqüência, tão temida nos compêndios escolares, realiza-se como via de recuperação da oralidade e do popular, que não se confunde com populismo. Nem reprodução lingüística nem reprodução da realidade regional. A apropriação dolorosa da palavra pelo in-fans - o que não fala revela-se uma leitura obstinada do mundo, enfim transformado no universo sem fronteiras da linguagem.

\section{Referências Bibliográficas}

SENNA, Homero. "Revisão do Modernismo". República das letras. 20 entrevistas com escritores. Rio de Janeiro: São José, 1957.

SCHMIDT, Augusto Frederico et al. "Discurso de Graciliano Ramos". Homenagem a Graciliano Ramos. Rio de Janeiro: [s.n.], 1943.

CARPEAUX, Otto Maria. "Visão de Graciliano Ramos". Origens e fins. Rio de Janeiro: Casa do Estudante do Brasil, 1943.

RAMOS, Graciliano. Memórias do cárcere. Rio de Janeiro: José Olympio, 1953.

LEITÃO, Cláudio. "Posfácio". Em: RAMOS, Graciliano. Infância. Rio de Janeiro: Record, 2003.

RAMOS, Graciliano. Infância. Rio de Janeiro: Record, 2003.

${ }^{17}$ RAMOS, 2003, p. 24. 


\section{Resumo}

Estudo de Infância, de Graciliano Ramos, com ênfase na reflexão sobre os conflitos que envolvem, na obra desse escritor, texto e história, sujeito e discurso, memória e imaginação.

\section{Résumé}

Étude sur le livre Infância de Graciliano Ramos, qui met en évidence les conflits entre le texte et la mémoire, entre le sujet et le discours, entre la mémoire et l'imagination. 